\title{
Renal Ammonia and Glutamine Metabolism during Liver Insufficiency-induced Hyperammonemia in the Rat
}

\author{
Cornelis H. C. Dejong, Nicolaas E. P. Deutz, and Peter B. Soeters \\ Department of Surgery, Biomedical Center, University of Limburg, Maastricht, The Netherlands
}

\begin{abstract}
Renal glutamine uptake and subsequent urinary ammonia excretion could be an important alternative pathway of ammonia disposal from the body during liver failure (diminished urea synthesis ), but this pathway has received little attention. Therefore, we investigated renal glutamine and ammonia metabolism in mildly hyperammonemic, portacaval shunted rats and severely hyperammonemic rats with acute liver ischemia compared to their respective controls, to investigate whether renal ammonia disposal from the body is enhanced during hyperammonemia and to explore the limits of the pathway. Renal fluxes, urinary excretion, and renal tissue concentrations of amino acids and ammonia were measured $24 \mathrm{~h}$ after portacaval shunting, and 2, 4, and $6 \mathrm{~h}$ after liver ischemia induction and in the appropriate controls.
\end{abstract}

Arterial ammonia increased to $247 \pm 22 \mu \mathrm{M}$ after portacaval shunting compared to controls $(51 \pm 8 \mu \mathrm{M})(P<0.001)$ and increased to $934 \pm 54 \mu \mathrm{M}$ during liver ischemia $(P<0.001)$. Arterial glutamine increased to $697 \pm 93 \mu \mathrm{M}$ after portacaval shunting compared to controls $(513 \pm 40 \mu \mathrm{M})(P<0.01)$ and further increased to $3781 \pm 248 \mu \mathrm{M}$ during liver ischemia $(P$ $<0.001)$. In contrast to controls, in portacaval shunted rats the kidney net disposed ammonia from the body by diminishing renal venous ammonia release (from $267 \pm 33$ to $-49 \pm 59 \mathrm{nmol}$ / $100 \mathrm{~g}$ body wt per min) and enhancing urinary ammonia excretion from $113 \pm 24$ to $305 \pm 52 \mathrm{nmol} / 100 \mathrm{~g}$ body wt per min (both $P<0.01$ ). Renal glutamine uptake diminished in portacaval shunted rats compared to controls $(-107 \pm 33$ vs. $-322 \pm 41 \mathrm{nmol} / 100 \mathrm{~g}$ body wt per $\mathrm{min})(P<0.01)$. However, during liver ischemia, net renal ammonia disposal from the body did not further increase $(294 \pm 88 \mathrm{vs} .144 \pm 101 \mathrm{nmol} / 100$ g body wt per min during portacaval shunting versus liver ischemia ). Renal glutamine uptake was comparable in both hyperammonemic models.

These results indicate that the rat kidney plays an important role in ammonia disposal during mild hyperammonemia. However, during severe liver insufficiency induced-hyperammonemia, ammonia disposal capacity appears to be exceeded. (J. Clin. Invest. 1993. 92:2834-2840.) Key words: ammonia • glutamine $\bullet$ hepatic encephalopathy $\bullet$ liver failure $\bullet$ kidney

Address correspondence to Dr. Nicolaas E. P. Deutz, Department of Surgery, Biomedical Center, University of Limburg, PO Box 616, NL6200 MD Maastricht, The Netherlands.

Received for publication 31 December 1992 and in revised form 7 July 1993

J. Clin. Invest.

(c) The American Society for Clinical Investigation, Inc.

$0021-9738 / 93 / 12 / 2834 / 07 \quad \$ 2.00$

Volume 92, December 1993, 2834-2840

\section{Introduction}

Liver disease, whether acute or chronic, is usually accompanied by diminished hepatic urea synthesis capacity, depriving the body of its main route of ammonia detoxification (1). This, combined with the usually existing intra- and extrahepatic portasystemic shunting, leads to hyperammonemia (1), activating alternative pathways of ammonia detoxification. The most important of these alternative pathways probably is the synthesis of the amino acid glutamine from equimolar amounts of glutamate and ammonia (2). It is not generally recognized, however, that glutamine synthesis and subsequent expansion of tissue and plasma free glutamine pools is only a temporary and limited way of ammonia detoxification. To get the ammonia out of the body in a situation of diminished or absent urea synthesis, glutamine has to be transported to and metabolized in the kidney, after which the ammonia can be excreted into the urine.

Arterial glutamine concentrations are generally elevated during liver insufficiency-induced hyperammonemia, a phenomenon thought to be caused by enhanced skeletal muscle glutamine synthesis and release (1). Because glutamine is the primary substrate for renal ammoniagenesis (3), the high glutamine concentrations could theoretically enhance renal ammonia disposal, and in the past some data have provided support for this theory (4-8). Thus, although in cirrhotic patients the kidney continued to release ammonia into the circulation $(5,9)$, this release decreased at elevated ammonia concentrations (5). Similarly, artificial hyperammonemia in healthy volunteers turned the kidney into an organ of net ammonia uptake from the circulation (6), also suggesting enhanced renal ammonia excretion. However, the role of the amino acid glutamine in these metabolic processes is unclear and virtually no literature exists concerning the relation between renal ammonia and glutamine metabolism during liver insufficiency and the related hyperammonemia.

Hyperammonemia is generally thought to be an important factor in the pathophysiology of hepatic encephalopathy (1). In the treatment of liver disease, therefore, therapy is focused on keeping arterial ammonia levels low and within narrow limits. Although standard therapy aims at reducing intestinal ammonia liberation, it should be realized that especially the kidney also is an important ammonia producing organ (10). Therefore, the kidney could be a second target organ in developing ammonia-lowering modalities in the treatment of liver failure.

Despite the pivotal role of the kidney in nitrogen disposal and ammonia- and glutamine-related acid-base regulation (3, 9), little is known about renal nitrogen metabolism during liver insufficiency and the related hyperammonemia. Therefore, the present experiments were designed to investigate the role of the kidney in ammonia and glutamine metabolism during liver disease. Specifically, we were interested in renal ammo- 
nia disposal from the body during liver insufficiency-induced mild and severe hyperammonemia. To this purpose we compared renal ammonia and glutamine metabolism in mildly hyperammonemic portacaval shunted rats with controls, and in addition, rats with severe hyperammonemia, induced by acute liver ischemia, were compared with their appropriate controls.

The results show that in the rat, renal ammonia and glutamine metabolism plays an important role in ammonia disposal during mild portacaval shunting-induced hyperammonemia. However, during severe liver ischemia-induced hyperammonemia ammonia disposal is not additionally enhanced, providing evidence that in this situation maximal renal ammonia disposal capacity is exceeded.

\section{Methods}

Animals. Male Wistar rats $(300 \pm 25 \mathrm{~g}, n=63)$ housed under standard conditions ( $12 \mathrm{~h}$ light/dark cycle, standard lab chow and water ad lib) were used throughout. Rats were maintained in accordance with the recommendations of the Guide for the Care and Use of Laboratory Animals, as applied in our institute.

Groups. The following experimental groups were studied: portacaval shunting $(\mathrm{PCS})^{1}$; control, laparotomy and manipulations as in PCS rats, but without shunting $(\mathrm{CON})$; and acute liver ischemia induction (ALI).

Experimental design (11). Surgery was carried out under ether anesthesia at constant temperature $\left(37 \pm 1^{\circ} \mathrm{C}\right)$. On day 0 , rats were randomized for either construction of a portacaval shunt (by the button method) (PCS-group; $n=55$ ) or sham surgery (CON-group; $n=8$ ). On day 1 , all rats of the CON group and some randomly selected PCS rats (PCS0-group; $n=8$ ) were subjected at $t=0 \mathrm{~h}$ to the sampling procedures described below. These two groups were compared to address the role of the kidney in mild liver insufficiency-induced hyperammonemia. Also on day 1, half of the remaining PCS rats were subjected at $t=0 \mathrm{~h}$ to acute liver ischemia induction by hepatic artery ligation, and sampling 2, 4, or 6 h later (ALI2, 4 or 6 group; $n=8$ per time point). The remainder underwent a sham procedure at $t=0$ in which the hepatic artery was identified but not ligated, and sampling was performed 2,4 , or $6 \mathrm{~h}$ later (PCS2, 4 or 6 group; $n=7$ or 8 per time point ). The latter two groups were compared to address the role of the kidney during severe liver insufficiency-induced hyperammonemia.

Miscellaneous. Immediately following hepatic artery ligation and every hour thereafter $1 \mathrm{ml}$ of a $5 \%$ glucose solution was given intraperitoneally to prevent hypoglycemia (11). Rats subjected to hepatic artery identification (PCS2, 4 and 6 groups) received normal saline intraperitoneally. Hourly temperature was measured and level of consciousness was judged using a 6 stage coma scale as described previously (12) (scale 0 to 5; $0=$ normal, $5=$ coma). During acute liver ischemia, hepatic encephalopathy progressed to loss of spontaneous righting reflex at $t=6 \mathrm{~h}$ as described previously $(11,12)$, but no coma was observed. In all other rats no major behavioral changes were observed.

Sampling. Sampling procedures were performed as described in detail recently (13). Briefly, rats were overnight fasted before sampling. Rectal temperature was maintained at preoperative levels: ALI rats $34 \pm 1^{\circ} \mathrm{C}$, other rats $37 \pm 1^{\circ} \mathrm{C}(11)$. Micro-catheters were inserted into the left jugular vein, right carotid artery, left renal vein, and left ureter and cemented in place with cyanoacrylate adhesive. For renal plasma flow determination, a primed, constant $1 \mathrm{mM}$ para-aminohippuric acid (Sigma Chemical Co., St. Louis, MO) infusion was given into the jugular vein $(0.08 \mathrm{ml} / \mathrm{min})$, including a 30 -min equilibration period to attain steady state $(11,13,14)$. At steady state, a 15 -min urine collection was done on ice, quantified $(\sim 7 \mu \mathrm{l} / \mathrm{min})$, diluted with icecold distilled water, and immediately immersed in liquid nitrogen.

1. Abbreviations used in this paper: ALI, acute liver ischemia; CON, control; ONEWAY, one-way ANOVA; PCS, portacaval shunting.
Next, $1 \mathrm{ml}$ of blood was withdrawn simultaneously from the renal vein and carotid artery. Finally, the kidney was frozen in liquid nitrogen. Rats were killed by an overdose of the anesthetic. The resulting arterial para-aminohippuric acid concentrations $(<70 \mu \mathrm{M})$ are not likely to influence renal ammoniagenesis (15). Also, our urine data in control rats are comparable to studies in which no para-aminohippuric acid was used $(15,16)$, providing evidence for the reliability of this urine sampling method.

Biochemical analysis. Samples were kept on ice during processing. Hematocrit was obtained with a microfuge. Centrifugations were performed at $4^{\circ} \mathrm{C}$ during $5 \mathrm{~min}$ at $8,800 \mathrm{~g}$. Plasma was put in liquid nitrogen within $20 \mathrm{~min}$. Plasma and tissue samples were stored at $-70^{\circ} \mathrm{C}$ until further processing. Tissue ammonia, amino acids, and water content were determined in $5 \%$ sulfosalicylic acid (wt/vol) extracts $(11,17)$. In plasma and urine, ammonia and urea were determined enzymatically, and amino acids by HPLC technique as described previously $(11,13)$. Para-aminohippuric acid was determined by standard techniques after deacetylation $\left(45 \mathrm{~min}, 100^{\circ} \mathrm{C}\right.$; reference 11 ). The coefficient of variance for all determinations was $\leq 4 \%$ (e.g., $4 \%$ for ammonia, $2 \%$ for glutamine; reference 11 ).

$p H$ Measurements. In some CON, PCS6, and ALI6 rats ( $n=3$ per group) arterial blood was sampled anaerobically for blood $\mathrm{pH}$ at the beginning and end of the 15-min urine collection. Finally, urine $\mathrm{pH}$ was measured in bladder urine. Samples were kept on ice and determined on an ABL520 blood gas analyzer (Radiometer, Copenhagen, Denmark).

Calculations. Urea values were corrected for ammonia. Plasma para-aminohippuric acid concentrations were calculated using whole blood para-aminohippuric acid concentration and hematocrit. Renal plasma flow ( $\mathrm{ml} / \mathrm{min}$ ) was calculated from the amount of para-aminohippuric acid infused and renal venous-arterial para-aminohippuric acid extraction using standard equations $(11,13,18)$. Fluxes were calculated as renal plasma flow times $\mathrm{V}-\mathrm{A}$ difference $(\mathrm{nmol} / 100 \mathrm{~g}$ body wt per min per 2 kidneys). Due to technical failure renal plasma flow was not available in all animals (see Results). Therefore, the flux data obtained by using the individual renal plasma flow were compared with the flux data obtained by using the mean renal plasma flow per group per time point. Because the absolute values obtained were similar, and not statistically different (Mann Whitney $U$ test), mean renal plasma flow was used for flux calculations. Positive values signify net efflux, negative values reflect net uptake. Urinary excretion was calculated as urine production times urinary concentration and also expressed per two kidneys ( $\mathrm{nmol} / 100 \mathrm{~g}$ body wt per $\mathrm{min}$ ). Total renal ammoniagenesis was calculated as ammonia flux plus urinary ammonia excretion. Net renal ammonia disposal from or addition to body ammonia pools was calculated as urinary excretion minus flux. The fraction of ammonia excreted in the urine was calculated as (urinary ammonia excretion/total renal ammoniagenesis) $\times 100 \%$.

Statistics (19). Data presented are means \pm SEM, $P<0.05$ was considered significant. The Mann Whitney- $U$ nonparametric test was used to test for differences between groups at specific time points (which is especially important for comparison of the PCSO and CON group). The effect of treatment (PCS or ALI) on the above described parameters was initially analyzed using a two-way ANOVA in which time and group were the main effects. Time period effects were then separately analyzed for each treatment by one-way ANOVA (ONEWAY) in which time period was the main effect. The ONEWAY procedure was followed by Scheffé multiple post hoc comparison if the ONEWAY showed significant differences. The Wilcoxon nonparametric test was used to test whether fluxes were significantly different from zero. Results of statistics are given in detail in the tables; for readability only main statistical effects are shown in the figures.

\section{Results}

Arterial concentrations (Table I). Arterial concentrations were comparable to those described previously in the same models (11). Arterial ammonia concentrations (Fig. 1) were elevated 
Table I. Arterial Concentrations

\begin{tabular}{lcccccccc}
\hline & CON 0 & PCS 0 & PCS 2 & PCS 4 & PCS 6 & ALI 2 & ALI 4 & ALI 6 \\
\hline $\mathrm{pH}_{\text {pre }}$ & $7.386 \pm .033$ & ND & ND & ND & $7.369 \pm .007$ & ND & ND & $7.410 \pm .030^{\mathrm{k}}$ \\
$\mathrm{pH}_{\text {post }}$ & $7.391 \pm .059$ & ND & ND & ND & $7.406 \pm .025$ & ND & ND & $7.421 \pm .042$ \\
AMM & $51 \pm 8$ & $247 \pm 22^{\mathrm{m}}$ & $231 \pm 30$ & $195 \pm 35$ & $169 \pm 21$ & $1044 \pm 69^{\mathrm{m}}$ & $820 \pm 37^{\mathrm{m}}$ & $934 \pm 54^{\text {cfim }}$ \\
UREA & $8.4 \pm .5$ & $7.7 \pm .4$ & $8.1 \pm .3$ & $8.2 \pm .5$ & $6.5 \pm .3^{\text {prs }}$ & $6.6 \pm .1^{1}$ & $5.2 \pm .3^{\text {r }}$ & $4.4 \pm .3^{\text {cfilpr }}$ \\
GLU & $37 \pm 3$ & $63 \pm 5^{\mathrm{m}}$ & $32 \pm 6^{\mathrm{q}}$ & $41 \pm 7$ & $45 \pm 7$ & $92 \pm 12^{1}$ & $180 \pm 8^{\mathrm{m}}$ & $272 \pm 14^{\text {cfimprs }}$ \\
GLN & $513 \pm 40$ & $697 \pm 93^{\mathrm{k}}$ & $594 \pm 34$ & $641 \pm 33$ & $689 \pm 53$ & $1852 \pm 71^{\mathrm{m}}$ & $2959 \pm 182^{\mathrm{m}}$ & $3781 \pm 248^{\text {cfimprs }}$
\end{tabular}

Data are means \pm SEM in $\mu \mathrm{M}$, except urea in $\mathrm{mM}$, and $\mathrm{pH}$. ND: not determined. Symbols: two way ANOVA for differences between ALI and PCS (time and group effects); $t=0$ to $t=6 \mathrm{hr}:{ }^{\mathrm{a}} P<0.05,{ }^{\mathrm{b}} P<0.01,{ }^{\mathrm{c}} P<0.001 ; t=2$ to $t=6 \mathrm{~h}$ : ${ }^{\mathrm{d}} P<0.05,{ }^{\mathrm{e}} P<0.01,{ }^{\mathrm{f}} P<0.001 ; t=4$ to $t=6 \mathrm{~h}:{ }^{8} P<0.05,{ }^{\mathrm{h}} P<0.01,{ }^{\mathrm{i}} P<0.001$. Mann Whitney- $U$ nonparametric test for differences at specific time points between CON and $P C S 0$, and between ALI and PCS: ${ }^{k} P<0.05,{ }^{1} P<0.01,{ }^{\mathrm{m}} P<0.001$. Wilcoxon test: ${ }^{+}$not significantly different from zero. One way ANOVA (ONEWAY) for time effects within groups ${ }^{\mathrm{D}} P<0.05$; Scheffé post hoc comparison for differences within group: ${ }^{\mathrm{q}} \mathrm{vs} . t=0,{ }^{\mathrm{r}} \mathrm{vs} . t=2,{ }^{\mathrm{s}} \mathrm{vs} . t=4$. $\mathrm{pH}_{\text {pre/post }}$ : Arterial blood sampled at the beginning/end of the 15 -min urine collection.

in PCS0 compared with CON rats and were grossly elevated in ALI rats compared to PCS2, 4, and 6 controls. Arterial concentrations of glutamine (Fig. 3) were elevated in PCSO compared with CON rats. In ALI rats compared with the PCS2, 4, and 6 groups an increase of glutamine levels to $\sim 3,800 \mu \mathrm{M}$ at $t=6 \mathrm{~h}$ was observed. Although arterial $\mathrm{pH}$ at the start of urine collections was slightly higher in ALI6 than in PCS6 rats, it did not differ from CON rats and was in the physiological range.

Renal ammonia handling (Tables II-V, Figs. 1 and 2). Renal plasma flow did not significantly differ between groups ( Table II). In CON rats, net ammonia release into the circulation was observed (Figure 1, right upper panel). In PCS0 rats this ammonia release into the circulation stopped, providing evidence that the kidney plays a role in the adaptation to mild hyperammonemia. Comparison of the ALI group with their PCS controls subjected to hepatic artery identification (PCS2, 4 , and 6 groups), revealed no overall significant differences between these groups: ammonia was released into the circulation in both groups at most time points. However, it must be emphasized that in PCS4 and 6 rats, ammonia release was not significantly different from zero, in contrast to ALI4 and 6 rats. The cause of differences in the time course of ammonia release between these groups is unclear, specifically the ammonia release in the PCS2 group, but might be related to a different response to the laparotomy at $t=0 \mathrm{~h}$ and subsequently elevated arterial glucocorticoid levels (20).

Urinary ammonia excretion (Fig. 1, left lower panel) was significantly higher in PCSO compared with CON rats. In ALI
Arterial Concentration

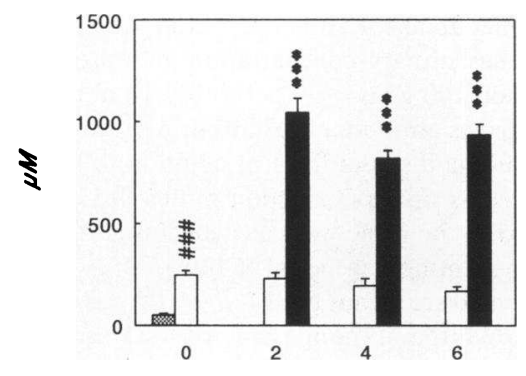

Urinary Excretion

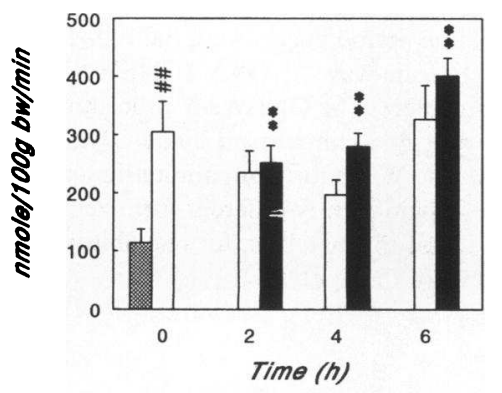

CON
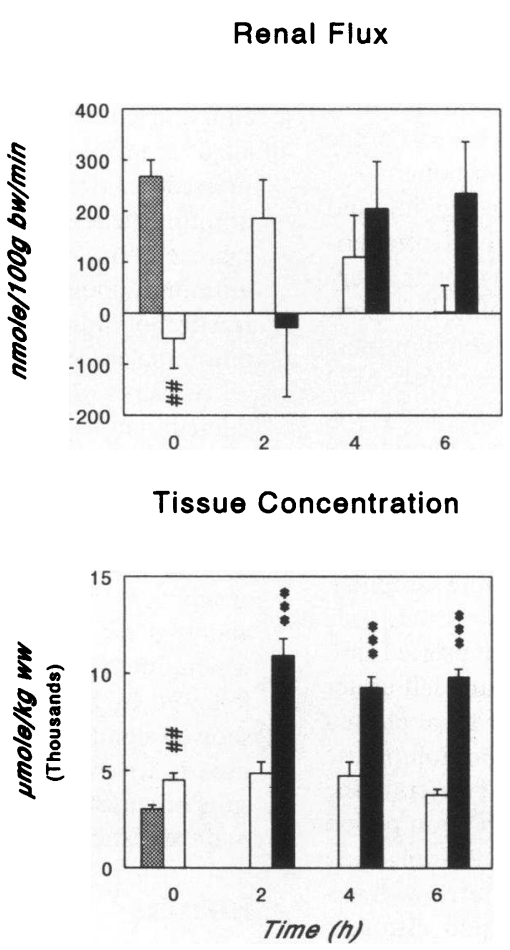

Figure 1. Ammonia: arterial concentrations (left upper graph; $\mu \mathrm{M}$ ), renal fluxes (right upper graph; nmole/ $100 \mathrm{~g}$ body wt per min per two kidneys), urinary excretion (left lower graph; $\mathrm{nmol} / 100 \mathrm{~g}$ body wt per min per two kidneys) and renal tissue concentrations ( right lower graph; $\mu \mathrm{mol} / \mathrm{kg}$ wet wt) in control rats (hatched bars), portacaval shunted rats (open bars) and in rats with acute liver ischemia (filled bars). Data are means \pm SEM; $n=7$ or 8 per group. Statistics: ANOVA was used for comparison between PCS and ALI groups (main effects time period and group); ${ }^{*} P<0.05$; ${ }^{* *} P<0.01 ;{ }^{* * *} P<0.001$. Mann Whitney- $U$ nonparametric test was used for differences between the PCS0 and CON group; ${ }^{*} P<0.01 ;{ }^{* *} P$ $<0.01 ; * * *=0.001$. Results of statistical analysis are given in more detail in the tables. 
Table II. Renal Metabolite Fluxes and Renal Plasma Flow

\begin{tabular}{|c|c|c|c|c|c|c|c|c|}
\hline & CON 0 & PCS 0 & PCS 2 & PCS 4 & PCS 6 & ALI 2 & ALI 4 & ALI 6 \\
\hline$R P F^{(n)}$ & $3.0 \pm 0.6^{(5)}$ & $2.7 \pm 0.3^{(8)}$ & $4.0 \pm 1.4^{(6)}$ & $3.8 \pm 0.7^{(6)}$ & $2.7 \pm 0.6^{(6)}$ & $2.5 \pm 0.4^{(6)}$ & $2.7 \pm 0.4^{(7)}$ & $2.3 \pm 0.6^{(6)}$ \\
\hline AMM & $267 \pm 33$ & $-49 \pm 49^{\neq 1}$ & $186 \pm 75$ & $110 \pm 82^{+}$ & $2 \pm 53^{\star}$ & $-28 \pm 136^{*}$ & $204 \pm 93$ & $234 \pm 102$ \\
\hline UREA & $598 \pm 340^{\neq}$ & $-766 \pm 287^{k}$ & $-776 \pm 456^{*}$ & $-1475 \pm 763^{*}$ & $-795 \pm 452^{+}$ & $-696 \pm 336^{*}$ & $-577 \pm 150$ & $-414 \pm 170^{+}$ \\
\hline GLU & $37 \pm 11$ & $15 \pm 20^{+}$ & $56 \pm 16$ & $62 \pm 19$ & $43 \pm 12$ & $48 \pm 26^{*}$ & $34 \pm 13$ & $66 \pm 24$ \\
\hline GLN & $-322 \pm 41$ & $-107 \pm 33^{1}$ & $-300 \pm 42^{q}$ & $-326 \pm 54^{q}$ & $-163 \pm 30^{\mathrm{ps}}$ & $-180 \pm 79^{*}$ & $-274 \pm 53$ & $-140 \pm 145^{*}$ \\
\hline
\end{tabular}

Data are means \pm SEM in $\mathrm{nmol} / 100 \mathrm{~g}$ body wt per min per 2 kidneys, except renal plasma flow (RPF) in ml/100 g body wt per min per $2 \mathrm{kidneys}$ (number of successful renal plasma flow measurements in parentheses). For significance symbols, see Table $\mathrm{I}$.

rats compared with their PCS2, 4, and 6 controls, urinary ammonia excretion was slightly higher. Kidney ammonia (Fig. 1, right lower panel) concentrations were elevated in PCSO compared with CON rats, and increased in ALI compared with their PCS2, 4, and 6 controls.

The overall effect of these changes in renal ammonia fluxes and urinary excretion is easier to interpret by looking at the kidney as an organ of net ammonia disposal from or addition to the body ammonia pools (Fig. 2, Table V). In CON rats ammonia release into the renal vein exceeds urinary ammonia excretion and therefore in this group the kidney is an organ of net ammonia addition to the body pools (Fig. 2, left upper panel; negative disposal). In sharp contrast, in PCSO rats the kidney reversed to net ammonia disposal from the body ( $P$ $<0.01$, PCS0 vs. CON). The kidney also proved to be a net ammonia disposal organ in rats subjected to acute liver ischemia (ALI) induction, but in this group ammonia disposal was not significantly different from that observed in their portacaval shunted controls (PCS2, 4, and 6 groups). The mechanism of the switch to net ammonia disposal in the PCS0 compared to CON group appeared to be a decrease in total renal ammoniagenesis (Fig. 2, right upper panel $)(P<0.01)$ and an increase in the absolute urinary ammonia excretion as well as the fraction of total renal ammoniagenesis excreted in the urine (Fig. 2, lower panels $)(P<0.01)$. In the liver ischemia rats fractional ammonia excretion and total renal ammoniagenesis were similar to their PCS2, 4, and 6 controls, except for an elevated total renal ammoniagenesis at $t=6 \mathrm{~h}$ in the ALI group.

Renal glutamine handling (Tables 2-4, Fig. 3). In all groups glutamine was taken up by the kidneys (Fig. 3, right upper panel). In PCS0 rats glutamine uptake was decreased compared with CON rats, compatible with the decreased total renal ammoniagenesis. No differences in glutamine uptake were observed between ALI and PCS2, 4, and 6 rats, also compatible with the observed total renal ammoniagenesis.

Urinary glutamine excretion was comparable in PCSO and $\mathrm{CON}$ rats (Fig. 3, left lower panel). In ALI rats a progressive increase in urinary glutamine excretion was observed, reaching levels fivefold elevated at $t=6 \mathrm{~h}$ compared with PCS rats subjected to hepatic artery identification. However, urinary glutamine excretion still was less than $5 \%$ of renal glutamine uptake in the ALI group. Kidney glutamine levels (Fig. 3, right lower panel) were elevated in PCS0 compared with CON rats, and increased in ALI compared with PCS2, 4, and 6 rats.

\section{Discussion}

In the present experiments the role of the kidney in ammonia metabolism during liver insufficiency and the related hyperammonemia was studied. Specifically, we were interested in whether the kidney plays a role in ammonia disposal during hyperammonemia, and whether this disposal capacity has an upper limit during severe hyperammonemia. To address the first question, we compared renal ammonia handling in portacaval shunted rats with that in sham operated controls. Portacaval shunting is a reproducible rat model for studying various aspects of liver insufficiency, among which are the effects of mild hyperammonemia (21). To address the second part of the question, we compared renal ammonia metabolism in rats with acute liver ischemia with that in portacaval shunted rats subjected to hepatic artery identification (ALI versus PCS2, 4, and 6). Like portacaval shunting, the liver ischemia rat model is reproducible and has been used extensively to study various aspects of severe acute liver failure and hyperammonemia (11, 22,23 ). Theoretically, adaptation of the kidney to hyperammonemia could be assumed to require increased renal uptake

Table III. Urine Values

\begin{tabular}{lcccccccc}
\hline & CON 0 & PCS 0 & PCS 2 & PCS 4 & PCS 6 & ALI 2 & ALI 4 \\
\hline pH & $6.084 \pm .110$ & ND & ND & ND & $6.028 \pm .028$ & ND & ND & $5.921 \pm .063^{\mathrm{k}}$ \\
VOL & $134 \pm 34$ & $338 \pm 91^{\mathbf{k}}$ & $217 \pm 54$ & $229 \pm 66$ & $298 \pm 80$ & $408 \pm 273$ & $464 \pm 145$ & $637 \pm 105^{\text {bdhk }}$ \\
AMM & $113 \pm 24$ & $305 \pm 52^{1}$ & $235 \pm 37$ & $197 \pm 26$ & $327 \pm 58$ & $252 \pm 30$ & $280 \pm 23^{\mathrm{k}}$ & $401 \pm 31^{\text {bikprs }}$ \\
UREA & $266 \pm 108$ & $479 \pm 240$ & $566 \pm 207$ & $327 \pm 102$ & $598 \pm 115$ & $83 \pm 26^{\mathrm{k}}$ & $190 \pm 20$ & $223 \pm 42^{\text {aehkpr }}$ \\
GLU & $0.64 \pm 0.18$ & $1.31 \pm 0.28^{\mathbf{k}}$ & $0.79 \pm 0.16$ & $0.52 \pm 0.10^{\mathbf{q}}$ & $0.61 \pm 0.12^{\text {p }}$ & $1.89 \pm 0.59^{\mathrm{k}}$ & $2.94 \pm 0.73^{1}$ & $9.41 \pm 2.17^{\text {cfilprs }}$ \\
GLN & $0.26 \pm 0.06$ & $0.58 \pm 0.21$ & $0.45 \pm 0.10$ & $0.77 \pm 0.14$ & $0.91 \pm 0.07$ & $1.43 \pm 0.41^{1}$ & $2.64 \pm 0.39^{\mathrm{m}}$ & $6.29 \pm 1.22^{\text {cfilprs }}$ \\
\hline
\end{tabular}

Data are means \pm SEM in $n m o l / 100 \mathrm{~g}$ body wt per min ( 2 kidneys), except volume (VOL) $(\mu \mathrm{l} / \mathrm{h})$ and $\mathrm{pH}$. ND: not determined. For significance symbols see Table I. 
Table IV. Tissue Metabolite Concentrations and Water Content

\begin{tabular}{lcccccccc}
\hline & CON 0 & PCS 0 & PCS 2 & PCS 4 & PCS 6 & ALI 2 & ALI 4 & ALI 6 \\
\hline$\% \mathrm{H}_{2} \mathrm{O}$ & $74.6 \pm 0.6$ & $74.9 \pm 0.8$ & $73.1 \pm 0.5$ & $75.3 \pm 0.4$ & $75.2 \pm 0.6$ & $75.6 \pm 0.9^{\mathbf{k}}$ & $75.6 \pm 0.7$ & $76.8 \pm 0.5^{\text {be }}$ \\
$\mathrm{AMM}$ & $3019 \pm 194$ & $4535 \pm 353^{1}$ & $4884 \pm 577$ & $4766 \pm 711$ & $3759 \pm 298$ & $10932 \pm 879^{1}$ & $9284 \pm 563^{\mathrm{m}}$ & $9823 \pm 408^{\text {cfim }}$ \\
GLU & $3832 \pm 244$ & $3437 \pm 272$ & $3640 \pm 303$ & $3627 \pm 228$ & $3690 \pm 175$ & $4058 \pm 445$ & $4943 \pm 485^{\mathbf{k}}$ & $4528 \pm 318^{\text {behk }}$ \\
GLN & $-1060 \pm 149$ & $1621 \pm 174^{\mathrm{k}}$ & $1312 \pm 111$ & $1326 \pm 82$ & $1524 \pm 161$ & $3569 \pm 278^{\mathrm{m}}$ & $4745 \pm 236^{\mathrm{m}}$ & $8194 \pm 723^{\text {cfimrs }}$ \\
\hline
\end{tabular}

Data are means \pm SEM in $\mu \mathrm{mol} / \mathrm{kg}$ wet wt, except tissue water content $\left(\% \mathrm{H}_{2} \mathrm{O}\right)$. For significance symbols, see Table I.

of blood-derived glutamine, decreased ammonia release into the renal vein, and increased urinary ammonia excretion (6), either apart or in combination.

Ammonia. In the physiological situation, renal ammoniagenesis results from the de-amidation of glutamine mainly by intra-mitochondrial phosphate-dependent glutaminase $(3,4$, $20)$. Only minor quantities $( \pm 10 \%)$ are produced by the brush border membrane-bound $\gamma$-glutamyl transferase in the distal parts of the proximal tubule (4). In the physiological situation $\sim 70 \%$ of total renal ammoniagenesis is released into the renal vein, the remainder being excreted in the urine (3). Renal vein ammonia release and urinary ammonia excretion in $\mathrm{CON}$ rats in our study are comparable with literature $(3,16)$.

In $\mathrm{CON}$ rats, ammonia release into the renal vein was observed. In PCS0 rats, however, ammonia release into the renal vein stopped, and simultaneously urinary ammonia excretion was increased. These combined changes reversed the kidney from an organ of net ammonia addition to the body pools in CON rats, to an organ of net ammonia disposal in PCS0 rats. Another important observation was that total renal ammoniagenesis was diminished in PCSO compared with CON rats. Thus, the kidney appears to play a very important role in the adaptation to mild hyperammonemia by reducing total ammoniagenesis and increasing the fraction of total ammoniagenesis excreted in the urine, thereby rendering the kidney into an organ of net ammonia disposal.

Recently, we reported in the same models (11) that intestinal ammonia production was $314 \pm 74 \mathrm{nmol} / 100 \mathrm{~g}$ body $\mathrm{wt}$ per min in the PCS0 group. Because renal ammonia disposal in the present study in PCS0 rats was $260 \pm 78 \mathrm{nmol} / 100 \mathrm{~g}$ body wt per min, it appears that the altered renal ammonia handling during portacaval shunting is sufficient to compensate for most of the gut-derived ammonia entering the circulation during portacaval shunting. However, during liver ischemia, intestinal ammonia generation (11) by far exceeded the observed renal ammonia disposal in the present study, contributing to progressive hyperammonemia. In recent studies, we have shown that in these models brain (17) and muscle (11) play a role in am- monia uptake and glutamine release, although the role of skeletal muscle appears to have been overestimated in literature. Apparently, several organs contribute to the alternative ammonia detoxification pathway consisting of glutamine synthesis, glutamine transport to the kidney, and ammonia excretion in the urine. Also, because the lung is capable of producing and releasing considerable amounts of glutamine (24), the lung could play a role in the alternative ammonia detoxification pathway, but this remains to be established.

Comparison of rats with acute liver ischemia and their portacaval shunted controls (PCS2, 4, and 6) revealed that the kidney was an organ of net ammonia disposal in both groups. However, no differences in ammonia disposal were observed, nor were there any significant differences in the fraction of total ammoniagenesis excreted in the urine. Thus, it appears that in the acute liver ischemia model, during severe hyperammonemia, the renal capacity to enhance ammonia disposal is exceeded. This appears to be in agreement with results obtained in studying the effects of acidosis on renal ammonia excretion (3).

Glutamine. Conflicting results have been reported concerning glutamine fluxes across the normal rat kidney (14-16, 18, 25 ). Most of these studies show net renal glutamine uptake, but some don't (25). The present study provides additional evidence that the normal rat kidney is an organ of net glutamine uptake. In the PCS0 group glutamine uptake was diminished compared with $\mathrm{CON}$ rats, which could contribute to expansion of the free plasma and tissue glutamine pools. The reduced renal glutamine uptake was reflected in a diminished total renal ammoniagenesis in the PCS0 group. Glutamine uptake was similar in ALI rats and in their PCS2, 4, and 6 controls, compatible with the observation that renal ammonia disposal is not enhanced in ALI rats compared with their PCS2, 4, and 6 controls. Also, the similar glutamine uptake despite increased arterial glutamine concentrations in the ALI rats suggests that renal glutamine uptake and subsequent ammonia disposal is not solely regulated by arterial glutamine levels. The actual regulatory mechanism remains to be determined. Renal

Table V. Ammonia Detoxification

\begin{tabular}{lcccccccc}
\hline & CON 0 & PCS 0 & PCS 2 & PCS 4 & PCS 6 & ALI 2 & ALI 4 & ALI 6 \\
\hline PROD & $389 \pm 24$ & $256 \pm 25^{1}$ & $414 \pm 94$ & $307 \pm 79$ & $299 \pm 48$ & $235 \pm 147^{*}$ & $484 \pm 79$ & $636 \pm 104^{\text {hkpr }}$ \\
DISP & $-163 \pm 57$ & $260 \pm 78^{1}$ & $39 \pm 86^{*}$ & $58 \pm 84^{*}$ & $294 \pm 88$ & $99 \pm 97^{*}$ & $76 \pm 110^{*}$ & $144 \pm 101^{*}$ \\
\%EXCR & $30 \pm 6$ & $85 \pm 9^{1}$ & $63 \pm 11$ & $70 \pm 11$ & $90 \pm 11$ & $71 \pm 14$ & $67 \pm 11$ & $68 \pm 9$ \\
\hline
\end{tabular}

PROD: Total renal ammoniagenesis; DISP: ammonia disposal; \%EXCR: percentage of total ammoniagenesis excreted in the urine. Data are means \pm SEM in nmol/100g body wt per min per 2 kidneys, except \%EXCR. For significance symbols, see Table I. 
Disposal
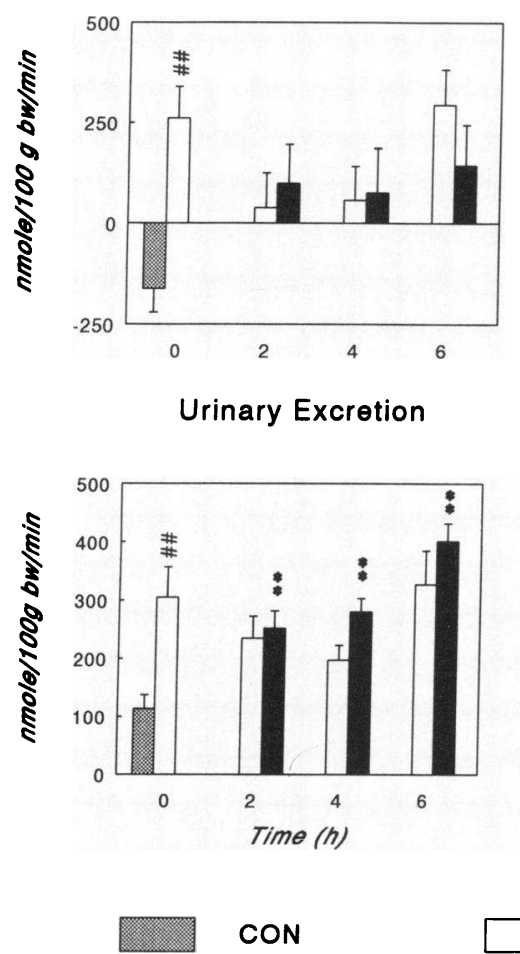

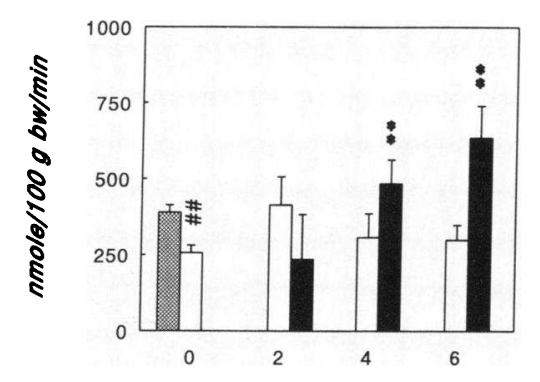

Fractional Ammonia Excretion

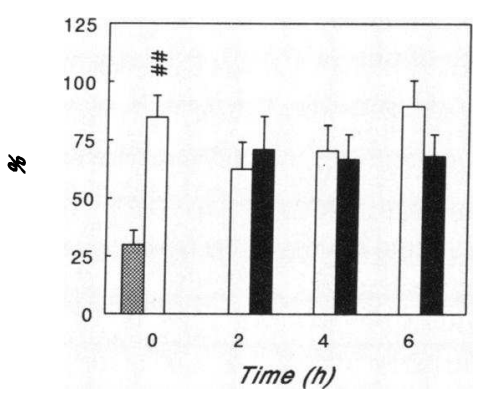

PCS
Renal ammoniagenesis

Figure 2. Ammonia detoxification: renal ammonia disposal (urinary excretion minus flux) (left upper graph; $\mathrm{nmol} / 100 \mathrm{~g}$ body wt per min per two kidneys), total renal ammoniagenesis (flux + urinary excretion; right upper graph; $\mathrm{nmol} / 100 \mathrm{~g}$ body wt per min per two kidneys), urinary excretion (left lower graph; $\mathrm{nmol} / 100 \mathrm{~g}$ body wt per min per two kidneys) and fractional ammonia excretion (urinary ammonia excretion expressed as fraction of total ammoniagenesis; right lower graph; \%) in control rats (hatched bars), portacaval shunted rats (open bars), and in rats with acute liver ischemia (filled bars). Data are means \pm SEM; $n=7$ or 8 per group. For details on statistical procedures, see legend of Fig. 1. tissue glutamine levels were elevated in PCSO compared with CON rats, and increased during liver ischemia compared with their PCS2, 4, and 6 controls, suggesting that the unchanged urinary ammonia excretion in ALI rats is not due to substrate shortage for the glutaminase pathway. On the contrary, the similar kidney glutamate levels in PCSO and CON rats, and the only marginally increased glutamate levels during liver ischemia suggest that the glutaminase pathway is inhibited by high ammonia levels (2). This would be consistent with the enzyme activity (at a given substrate availability) playing a crucial role
Arterial Concentration

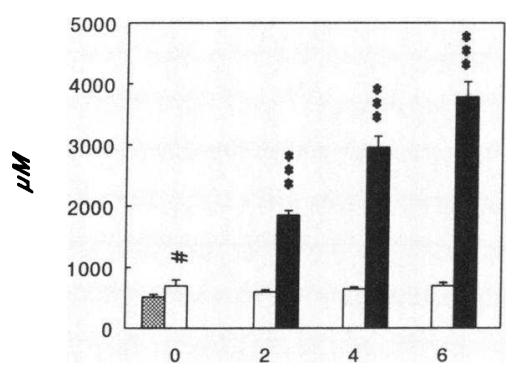

Urinary Excretion

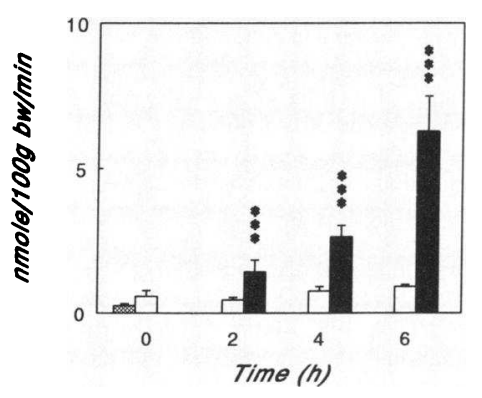

CON

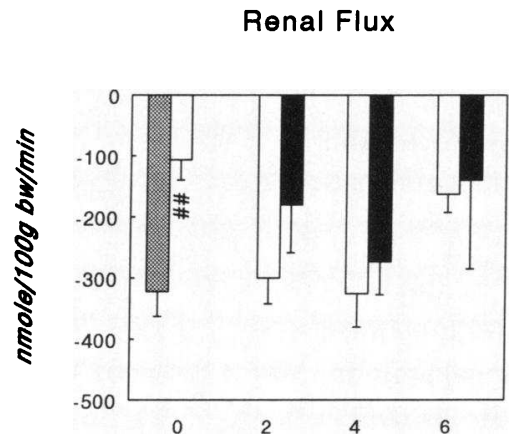

Tissue Concentration

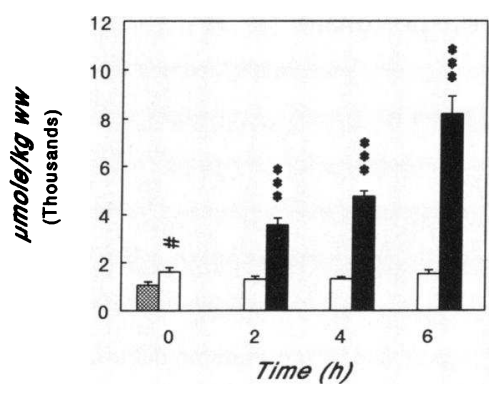

PCS

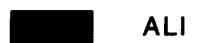

Figure 3. Glutamine: arterial concentrations (left upper graph; $\mu \mathrm{M}$ ), renal fluxes (right upper graph; $\mathrm{nmol} / 100 \mathrm{~g}$ body wt per min per two kidneys), urinary excretion (left lower graph; $\mathrm{nmol} / 100 \mathrm{~g}$ body wt per min per two kidneys) and renal tissue concentrations (right lower graph; $\mu \mathrm{mol}$ per $\mathrm{kg}$ wet wt) in control rats (hatched bars), portacaval shunted rats (open bars), and in rats with acute liver ischemia (filled bars). Data are means \pm SEM; $n=7$ or 8 per group. For details on statistical procedures, see legend of Fig. 1. 
in regulating ammonia excretion (8) and seems the best explanation for our observations. Because the kidney contains very little glutamine synthetase (26), this is not a likely explanation for the changes.

The effects of acid-base changes on kidney ammonia and glutamine metabolism have been extensively studied (for review see references 3 and 4). Metabolic acidosis, whether acute or chronic, induces enhanced renal glutamine extraction ( 7 , 18 ) and increased urinary ammonia excretion (7) at the expense of urea excretion, whereas total urinary nitrogen excretion as ammonia plus urea remains constant (14). In contrast, respiratory alkalosis in cirrhotic patients enhances renal venous ammonia release, thus reducing renal ammonia disposal (9). However, in the present studies, only minimal pH changes were observed within the physiological range as observed by others in the same model (22), making an influence of $\mathrm{pH}$ on the observed changes unlikely. Nonetheless, the changes in fraction of renal ammoniagenesis excreted in the urine closely resembled those observed in studies during acidosis. Thus, it is known that during acidosis the fraction of ammonia excreted in the urine rises to $70 \%$, thereby reversing the urine / renal vein ammonia partition ratio (normally $30 / 70$ as in reference 3 ). This might suggest that a common pathway is involved in acidosis- and hyperammonemia-induced enhanced urinary ammonia excretion, which does not seem to be mediated by arterial or urine $\mathrm{pH}$. However, the mechanism underlying the observed reversal of renal ammonia addition to the body pools in controls, as it changes to ammonia disposal during hyperammonemia, cannot be deduced from our experiments.

Recently, it has become increasingly clear that renal ammonia excretion into the urine cannot be explained simply as $\mathrm{pH}-$ dependent (the "diffusion-trapping" system discussed in reference 3). Instead, other factors (e.g., tubular urine flow, several ion exchangers, and the ammonia counter-current system) appear to be more important than tubular $\mathrm{pH}$ in the regulation of urinary ammonia excretion $(3,27,28,29)$. It is beyond the scope of this paper to discuss these regulatory mechanisms in detail, but if it were possible to influence any of these processes involved in ammonia excretion, this could provide a fruitful area for developing new therapeutics in the treatment of hyperammonemia.

Conclusion. This study shows that during portacaval shunting in rats, the kidney plays an important role in ammonia disposal during mild hyperammonemia by diminishing renal ammoniagenesis and enhancing the fraction of renal ammoniagenesis excreted in the urine, thereby turning into an organ of net ammonia disposal. During severe acute hyperammonemia induced by liver ischemia, however, the kidney does not additionally enhance net ammonia disposal from the body, providing evidence that in this situation the capacity of the renal ammonia system to excrete ammonia is exceeded.

\section{Acknowledgments}

The authors wish to thank Mr. H. M. H. van Eijk, Mrs. M. A. H. van der Heijden, and Mrs. M. A. Janssen for laboratory determinations.

\section{References}

1. Zieve, L. 1987. Pathogenesis of hepatic encephalopathy. Metab. Brain Dis. $2: 147-165$
2. Newsholme, E. A., and A. R. Leech. 1983. Biochemistry for the Medical Sciences. John Wiley \& Sons, Inc. New York.

3. Halperin, M. L., K. S. Kamel, J. H. Ethier, B. J. Stinebaugh, and R. L. Jungas. 1992. Biochemistry and physiology of ammonium excretion. In The Kidney; Physiology and Pathophysiology (D. W. Seldin and G. Giebisch, editors.) Raven Press Ltd., New York, 2645-2679.

4. Tannen, R. L. 1978. Ammonia metabolism. Am. J. Physiol. 235:F265F277.

5. Tyor, M. P., E. E. Owen, J. N. Berry, and J. F. Flanagan. 1960. The relative role of extremity, liver and kidney as ammonia receivers and donors in patients with liver disease. Gastroenterology. 39:420-424.

6. Owen, E. E., J. H. Johnson, and M. P. Tyor. 1961. The effect of induced hyperammonemia on renal ammonia metabolism. J. Clin. Invest. 40:215-221.

7. Owen, E. E., and R. R. Robinson. 1963. Amino acid extraction and ammonia metabolism by the human kidney during the prolonged administration of ammonium chloride. J. Clin. Invest. 42:263-276.

8. Welbourne, T. C., M. Weber, and N. Bank. 1972. The effect of glutamine administration on urinary ammonium excretion in normal subjects and patients with renal disease. J. Clin. Invest. 51:1852-1860.

9. Berry, J. N., J. F. Flanagan, E. E. Owen, and M. P. Tyor. 1959. The kidney as a source of blood ammonia in resting and hyperventilated cirrhotics. Clin. Res. 7:154-155.

10. Imler, M., J.-L. Schlienger, G. Chabrier, and C. Simon. 1986. Arterial ammonia changes of renal origin induced in the rat by acid and alkaline diets. Res. Exp. Med. 186:353-363.

11. Dejong, C. H. C., M. T. Kampman, N. E. P. Deutz, and P. B. Soeters 1992. Altered glutamine metabolism in rat portal drained viscera and hindquarter during hyperammonemia. Gastroenterology. 102:936-948.

12. Bosman, D. K., N. E. P. Deutz, A. A. de Graaf, R. W. N. van der Hulst, H. M. H. van Eijk, W. M. M. J. Bovée, M. A. W. Maas, G. G. A. Jörning, and R. A. F. M. Chamuleau. 1990. Changes in brain metabolism during hyperammonemia and acute liver failure: results of a comparative ${ }^{1} \mathrm{H}-\mathrm{NMR}$ spectroscopy and biochemical investigation. Hepatology. 12:281-290.

13. Dejong, C. H. C., N. E. P. Deutz, and P. B. Soeters. 1993. Metabolic adaptation of the kidney to hyperammonemia during chronic liver insufficiency in the rat. Hepatology. In press.

14. Welbourne, T. C. 1986. Effect of metabolic acidosis on hindquarter glutamine and alanine release. Metab. Clin. Exp. 35:614-618.

15. Welbourne, T. C., and P. D. Dass. 1988. Gamma glutamyltransferase contribution to renal ammoniagenesis in vivo. Pfluegers Arch. Eur. J. Physiol. 411:573-578.

16. Imler, M., G. Chabrier, C. Marescaux, and J. M. Warter. 1986. Effects of 2,4-dinitrophenol on renal ammoniagenesis in the rat. Eur. J. Pharmacol. 123:175-179.

17. Dejong, C. H. C., M. T. Kampman, N. E. P. Deutz, and P. B. Soeters. 1992. Cerebral cortex ammonia and glutamine metabolism during liver insufficiency-induced hyperammonemia in the rat. J. Neurochem. 59:1071-1079.

18. Phromphetcharat, V., and T. C. Welbourne. 1985. Renal glutamine extraction and gut/liver interaction in glutamine homeostasis. Contrib. Nephrol. 47:9-14.

19. Norusis, M. J. 1989. SPSS/PC+ V3.1 BASE MANUAL for the IBM $\mathrm{PC} / \mathrm{XT} / \mathrm{AT}$ and PS/2. SPSS Inc, Chicago.

20. Welbourne, T. C. 1990. Glucocorticoid control of ammoniagenesis in the proximal tubule. Semin. Nephrol. 10:339-349.

21. Mullen, K. D., and A. J. McCullough. 1989. Problems with animal models of chronic liver disease: Suggestions for improvement in standardization. Hep atology. 9:500-505.

22. Bosman, D. K., C. A. C. G. van den Buijs, J. G. de Haan, M. A. W. Maas, and R. A. F. M. Chamuleau. 1991. The effects of benzodiazepine receptor antagonists and partial inverse agonists on acute hepatic encephalopathy in the rat. Gastroenterology. 101:772-781.

23. Swain, M., R. F. Butterworth, and A. T. Blei. 1992. Ammonia and related amino acids in the pathogenesis of brain edema in acute ischemic liver failure in rats. Hepatology. 15:449-453.

24. Welbourne, T. C. 1988. Role of the lung in glutamine homeostasis. Contrib. Nephrol. 63:178-182.

25. Schröck, H., and L. Goldstein. 1981. Interorgan relationships for glutamine metabolism in normal and acidotic rats. Am. J. Physiol. 240:E519-E525.

26. Welbourne, T. C., V. Phromphetcharat, G. Givens, and S. Joshi. 1986 Regulation of interorgan glutamine flow in metabolic acidosis. Am. J. Physiol. 250:E457-E463.

27. Kikeri, D., A. Sun, M. L. Zeidel, and S. C. Hebert. 1992. Cellular $\mathrm{NH}_{4+} /$ $\mathrm{K}^{+}$transport pathways in mouse medullary thick limb of Henle. Regulation by intracellular pH. J. Gen. Physiol. 99:435-461.

28. DuBose, T. D., Jr., and D. W. Good. 1992. Chronic hyperkalemia impairs ammonium transport and accumulation in the inner medulla of the rat. J. Clin. Invest. 90:1443-1449.

29. Nagami, G. T. 1992. Effect of angiotensin II on ammonia production and secretion by mouse proximal tubules perfused in vitro. J. Clin. Invest. 89:925931. 